\title{
RESEARCH
}

Open Access

\section{Analysing the potential of hydrophilic adhesive systems to optimise orthodontic bracket rebonding}

Isabel Knaup ${ }^{1 *}$, Antonia Böddeker ${ }^{1}$, Katrin Tempel ${ }^{1}$, Eva Weber ${ }^{1}$, Jenny Rosa Bartz ${ }^{1}$, Marcia Viviane Rückbeil², Rogério Bastos Craveiro ${ }^{1}$, Yvonne Wagner ${ }^{3}$ and Michael Wolf ${ }^{1}$

\begin{abstract}
Introduction: Bond failure during fixed orthodontic treatment is a frequently occurring problem. As bracket rebonding is associated with reduced shear bond strength, the aim of the present investigation is to analyse the effect of different innovative rebonding systems to identify optimised rebonding protocols for orthodontic patient care.

Methods: Metallic brackets were bonded to the frontal enamel surfaces of 240 bovine lower incisors embedded in resin bases. Teeth were randomly divided into two major experimental groups: in group 1 a hydrophilic primer (Assure ${ }^{\mathrm{TM}}$ PLUS) was compared to commonly used orthodontic adhesives (Transbond $\mathrm{XT}^{\mathrm{TM}}$, BrackFix ${ }^{\circledR}$, Grengloo ${ }^{\mathrm{TM}}$ ) and a zero control. In group 2 different rebonding systems were analysed using a hydrophilic primer (Assure ${ }^{\mathrm{TM}}$ PLUS), a methyl methacrylate-consisting primer (Plastic Conditioner) and a conventional adhesive (Transbond XT ${ }^{\mathrm{M}}$ ). All teeth were tested for shear bond strength according to the DIN-13990 standard, the Adhesive Remnant Index and enamel fracture rate.

Results: The hydrophilic primer enhanced shear bond strength at first bonding (Assure ${ }^{\mathrm{TM}}$ PLUS $20.29 \pm 4.95 \mathrm{MPa}$ vs.

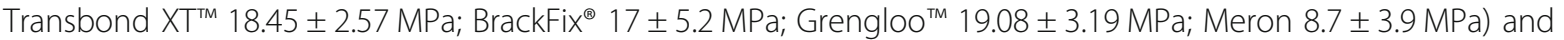
second bonding (Assure ${ }^{\mathrm{TM}}$ PLUS 16.76 $\pm 3.71 \mathrm{MPa}$ vs. Transbond XT'M $13.06 \pm 3.19 \mathrm{MPa}$ ). Using Plastic Conditioner did not seem to improve shear bond strength at rebonding $(13.57 \pm 2.94)$. When enamel etching was left out, required shear bond strength could not be achieved (Plastic Conditioner + Assure ${ }^{\mathrm{TM}}$ PLUS 8.12 \pm 3.34 MPa; Plastic Conditioner: $3.7 \pm 1.95 \mathrm{MPa}$ ). Hydrophilic priming systems showed decreased ARI-scores (second bonding: 2.63) and increased enamel fracture rates (first bonding: 55\%; second bonding 21,05\%).

Conclusions: Based on the present study we found that rebonding strength could be compensated by the use of hydrophilic priming systems. The additional use of a methyl methacrylate-consisting primer does not seem to enhance shear bond strength. No etching approaches resulted in non-sufficient bond strength.
\end{abstract}

Keywords: Rebonding, Second bonding, Orthodontics, Bracket, Shear bond strength

\footnotetext{
* Correspondence: iknaup@ukaachen.de

'Department of Orthodontics, RWTH Aachen University Hospital, Pauwelsstr. 30, 52074 Aachen, Germany

Full list of author information is available at the end of the article
}

(c) The Author(s). 2020 Open Access This article is licensed under a Creative Commons Attribution 4.0 International License, which permits use, sharing, adaptation, distribution and reproduction in any medium or format, as long as you give appropriate credit to the original author(s) and the source, provide a link to the Creative Commons licence, and indicate if changes were made. The images or other third party material in this article are included in the article's Creative Commons licence, unless indicated otherwise in a credit line to the material. If material is not included in the article's Creative Commons licence and your intended use is not permitted by statutory regulation or exceeds the permitted use, you will need to obtain permission directly from the copyright holder. To view a copy of this licence, visit http://creativecommons.org/licenses/by/4.0/. The Creative Commons Public Domain Dedication waiver (http://creativecommons.org/publicdomain/zero/1.0/) applies to the data made available in this article, unless otherwise stated in a credit line to the data. 


\section{Introduction}

Bond failure during fixed orthodontic treatment is an unpredictable problem that is usually the result either of the patient's accidentally applying inappropriate forces to the bracket or of a poor bonding strength [1]. Bonding performance depends on factors such as tooth type and position, type of bonding agents and curing methods, bracket types and materials, aging and attrition $[2,3]$. Prevalence varies between 2.8-12.3\%, whereas bracket failure of up to 2 brackets seems to be clinically acceptable [2, 4-7]. Because molars and second premolars are more often affected by bracket failure, some authors recommend bands for these teeth, but as bands affect esthetics and oral hygiene, their use is limited [2, $8-12]$. Lower teeth are more affected by bracket loss than upper teeth since saliva contamination during bracket positioning is more likely [3, 13-15].

Since premature bracket loss can lead to unwanted tooth movement and prolonged treatment duration, immediate rebonding is required [16, 17]. Different rebonding procedures are described: clinicians either reuse the failed bracket or they bond a new bracket. For bracket recycling, the remaining adhesive has to be removed from the bracket in either mechanic, thermic or chemical procedures using silicon polishers, sand blasting, flame-scarfing or acid treatment $[18,19]$. Remaining adhesive on the teeth is usually removed with slow rotating hard metal polishers, although micro damages remain a frequently observed phenomenon [20]. Concerning shear bond strength (SBS), literature shows heterogeneous results: some studies reported reduced SBS for rebonded or recycled brackets [1, 21-23], but others cannot confirm these findings [24]. However, authors assume that lower bond strength may be related to changes in the morphologic characteristics of the etched enamel surface as a result of the presence of adhesive remnants $[1,24]$.

To improve the rebonding capability, recently the adhesive systems Assure ${ }^{\text {tm }}$ PLUS (AS, Reliance ${ }^{\bullet}$ Orthodontic Products, Inc., Itasca, USA) and Plastic Conditioner (PC, Reliance ${ }^{\bullet}$ Orthodontic Products, Inc., Itasca, USA) with SBS enhancing characteristics have been introduced and might be a promising tool in the improvement of bracket rebonding. Assure ${ }^{\mathrm{Tu}}$ PLUS consists like other SBS enhancing products of the molecule hydroxyl ethyl methacrylate (HEMA) which is thought to assist with moisture control at bonding [25]. HEMA is initially known for the use in dentin adhesion because its hydrophilic properties and hydrophobic functional groups allow a better penetration and infiltration of monomers resulting in a better SBS after polymerisation [26-28]. Therefore, HEMA-consisting primers are also called hydrophilic primers. Plastic Conditioner consists of the molecules methyl methacrylate (MMA) and isobutyl methacrylate and is claimed to enhance the connection between composite and acrylic resin. In prosthodontics, MMA has been used for repairing prostheses, but it has also become popular in orthodontics for indirect bonding or bracket placement on acrylic teeth [29-32]. However, systematic information on rebonding might improve rebonding strength. Moreover, the effectiveness of additional enamel etching procedure has been questioned. It remains unclear, whether the use of those reagents alone or in combination might improve rebonding. Therefore, the aim of the present investigation was to evaluate the impact of different rebonding procedures and products on the SBS of orthodontic attachments in second bonding.

\section{Materials und methods}

\section{Trial design}

In this in vitro study metallic upper central incisor brackets with laser structured bases (Discovery ${ }^{\circ}$, DENT AURUM GmbH \& Co. KG, Ispringen, Germany) were bonded to the frontal enamel surfaces of commercially available bovine lower incisors (Rocholl $\mathrm{GmbH}$, Aglasterhausen, Germany) to test for shear bond strength (SBS) according to the DIN-13990 standard. All teeth were caries-free and didn't show any signs of fractures or breaks. They were stored in pure water of quality 3 (Ampuwa ${ }^{\circ}$, Fresenius Kabi Deutschland $\mathrm{GmbH}$, Bad Homburg vor der Höhe, Germany) at $4 \pm 2{ }^{\circ} \mathrm{C}$ according to DIN ISO-3696 standard and removed shortly before the trial. Teeth were randomly divided into groups, cleaned SuperPolish $^{\text {Tx }}$, Kerr Dental, Rastatt, Germany), rinsed and dried for further processing. Sample size was set to 20 specimens per group in accordance to the DIN-13990 standard that requires a minimum of 10 specimens and previous in vitro studies investigating shear bond strength $[16,33]$. The trial consisted of three parts.

\section{Conventional orthodontic bonding systems}

In part 1 commonly used light-curing adhesives were tested to assess reference values. Therefore, brackets were bonded on bovine teeth in the following manner: $35 \%$ phosphoric acid (Vococid $^{\circ}$, $\mathrm{VOCO}^{\circ} \mathrm{GmbH}$, Cuxhaven, Germany) was applied for 20 s, etching agent was removed using water spray, enamel surface was dried and coated with a primer, the bracket was placed using an adhesive paste, surpluses were removed, light curing was performed using a light-emitting diode (LED) device with a light intensity of $3000 \mathrm{~mW} / \mathrm{cm}^{2}$ (Mini LED $^{\mathrm{mm}}$, Acteon Germany GmbH, Düsseldorf, Germany). Therefore, the device was angled at 30 degrees and placed as close as possible to the bracket from each the mesial and distal side for $10 \mathrm{~s}$. Further specimens were 
bonded with a self-drying glass ionomer luting cement serving as a zero control.

The following groups were built:

- Transbond $^{\mathrm{Tm}} \mathrm{XT}$ primer + adhesive (TB XT, $3 \mathrm{M}$ Unitek GmbH, Neuss, Germany) $(n=20)$

- BrackFix ${ }^{\circ}$ primer + adhesive $\left(\mathrm{VOCO}^{\circ} \mathrm{GmbH}\right.$, Cuxhaven, Germany) ( $n=20)$

- Ortho Solo ${ }^{\mathrm{Tw}}$ primer + Grengloo $^{\mathrm{Tw}}$ adhesive (Ormco Corp., Orange, USA) $(n=20)$

- Meron glas ionomer luting cement $\left(\mathrm{VOCO}^{\circ} \mathrm{GmbH}\right.$, Cuxhaven, Germany) $(n=20)$

\section{Strength enhancing orthodontic bonding systems}

In part 2 brackets were bonded in the same manner, but the primer Assure $^{\mathrm{m}}$ PLUS (AS, Reliance ${ }^{\bullet}$ Orthodontic Products, Inc., Itasca, USA) was used instead of the TB XT primer. AS was applied in a thin layer for $10 \mathrm{~s}$ and carefully air dried prior to bracket placing with TB XT adhesive.

In addition, part 2 was intended to investigate on the effects of AS on bracket rebonding. Therefore, premature bracket loss was simulated as followed: brackets were bonded with TB XT as described above and debonding was performed with a universal testing machine (Z020, ZwickRoell GmbH \& Co. KG, Germany). The remaining adhesive was removed from the teeth with a hard metal polisher (Hager \& Meisinger $\mathrm{GmbH}$, Neuss, Germany) and new orthodontic attachments were placed on the same bovine teeth with either TB XT primer or AS primer and TB XT adhesive.

The following groups were built:

- AS + TB XT adhesive $(n=20)$

- AS + TB XT adhesive $(n=20)$ rebonding

- TB XT primer + adhesive $(n=20)$ rebonding

\section{Comparison of different rebonding systems}

In part 3 different rebonding procedures and product combinations including a methacrylate-consisting primer (Plastic Conditioner $=$ PC, Reliance ${ }^{\circ}$ Orthodontic Products, Inc., Itasca, USA) were compared. PC was applied in a thin layer before a primer was applied after $60 \mathrm{~s}$. In some specimens second bonding was performed without applying phosphoric acid.

The following groups were built:

- TB XT primer + TB XT adhesive $(n=20)$ rebonding

- PC + TB XT primer + TB XT adhesive $(n=20)$ rebonding

- PC $+\mathrm{AS}+\mathrm{TB}$ XT adhesive $(n=20)$ rebonding

Leaving out enamel etching

- PC, AS + TB XT adhesive $(n=20)$ rebonding
- PC, TB primer + TB XT adhesive $(n=20)$ rebonding

Debonding according to the DIN-13990 standard

The specimens of all three parts were embedded in polyurethane (CEM 9000, Cloeren Technology GmbH, Wegberg, Germany) in custom-made squared polytetrafluorethylene devices (Otto Schott Institute of Materials Research, University of Jena, Germany) to allow later placement in a universal testing machine (Fig. 1a). Each specimen was processed shortly before testing, stored in water at $37( \pm 2)^{\circ} \mathrm{C}$ for $24( \pm 2) \mathrm{h}$ after polymerisation and mounted into a universal testing machine (Z020, ZwickRoell GmbH \& Co. KG, Ulm, Germany) (Fig. 1b). The movement of the head and the magnitude of the applied force was electronically controlled and monitored via the software testXpert ${ }^{\circ}$ II (ZwickRoell GmbH \& Co. KG, Ulm, Germany). Prior to testing, 20 specimens were debonded to verify the procedure. The following parameters were recorded according to DIN-13990 standard [34]:

1. Shear bond strength (SBS): the bond strength was measured in shear mode at a crosshead speed of 1 $\mathrm{mm} / \mathrm{min}$ until bracket removal was achieved. The SBS needed to debond or initiate bracket fracture was recorded and then converted into pressure $(\mathrm{MPa})$ as a ratio of force per bracket surface area $\left(13.12 \mathrm{~mm}^{2}\right)$.

2. Adhesive remnant index (ARI): after bracket removal, the enamel surfaces were examined using a light microscope and the corresponding ARI assessed. The following 5-point scale classification based on Bishara and Trulove [35] was used: $1=$ no adherence of composite on the bracket base, $2=$ less than $10 \%$ of composite remaining on the bracket surface, $3=$ more than $10 \%$ but less than $90 \%$ of composite remaining on the bracket surface, $4=$ more than $90 \%$ of composite remaining on the bracket surface, and $5=$ all composite remaining on the bracket base.

3. Enamel fractures: after bracket removal, the enamel surfaces were examined using a light microscope and enamel fractures were scored using $10 \mathrm{x}$ magnification. ARI and enamel fracture were scored by one investigator who was not aware of the groups.

\section{Statistical analysis}

Data were recorded in Microsoft Excel files (Office version 365, Microsoft Corporation, Redmond, USA) and transferred to SAS software (PROC MIXED and PROC LOGISTIC, version 9.4, SAS Institute, Cary USA) for analysis. Methodical outliers were excluded. Graphics were created using GraphPad Prism (version 7, GraphPad software, San Diego, USA). 


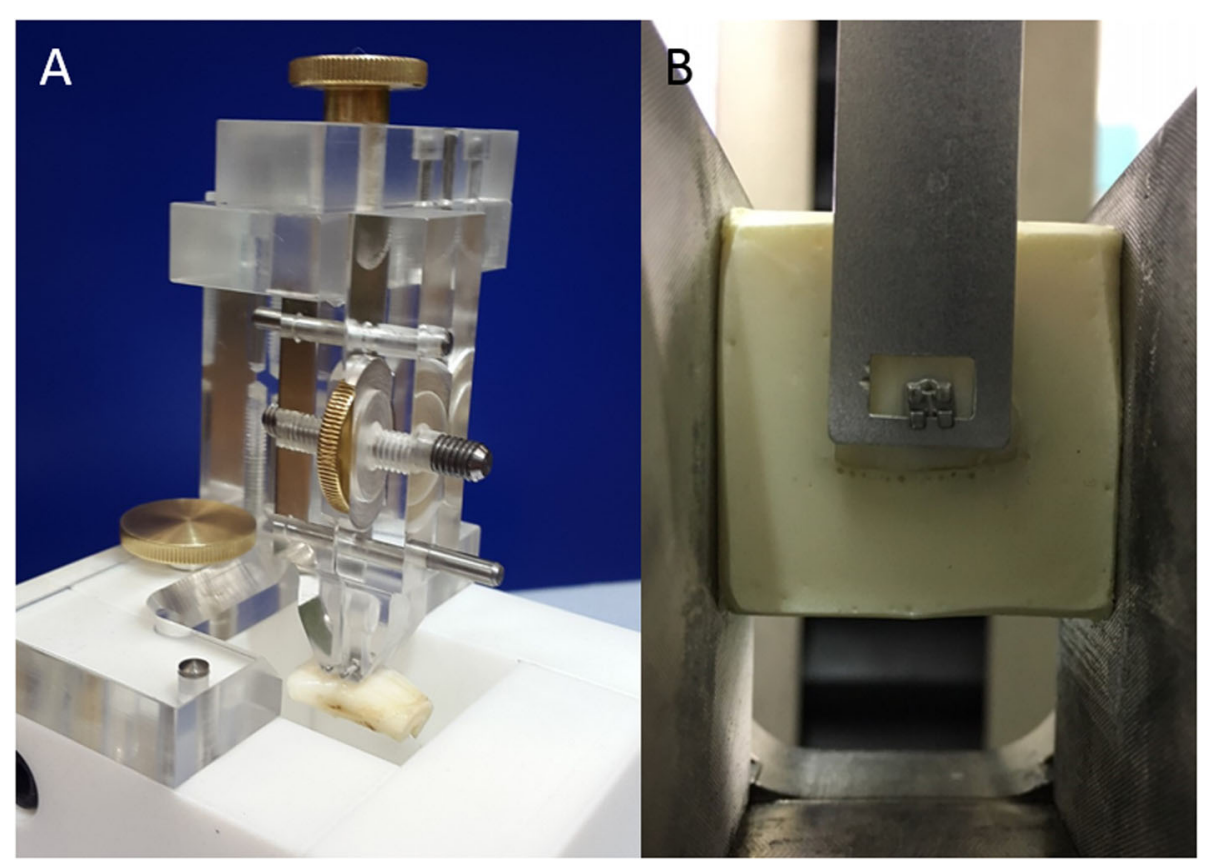

Fig. 1 Processing of the specimens. a Orthodontic attachments were bonded to lower bovine incisors and embedded in polyurethane in custom-made polytetrafluorethylene devices. b After polymerisation devices were unscrewed and the squared specimens were referred to the universal testing machine Zwick

Continuous data are shown as mean \pm standard deviation (SD), categorical outcomes as absolute and relative frequencies (\%). The outcomes SBS and ARI score were compared using a linear regression model, the outcome enamel damage using a logistic regression model with Firth's bias correction. Depending on the comparison, the models included either one independent factor or two independent factors and an interaction term. All relevant pairwise comparisons were tested using linear contrasts (lsmeans or lsmestimate option). To account for multiple comparisons, all $p$-values were adjusted using the simulation based adjustment by Edwards and Berry (with EPS $=5 \cdot 10^{-4}$ and $\mathrm{ACC}=2 \cdot 5 \cdot 10^{-4}$ ) [36]. A $p$ value $\leq 0.05$ was used to indicate statistically significant differences.

\section{Results}

\section{Bonding strength of analysed orthodontic bonding} systems

Shear bond strength (SBS) of TB XT $(18.45 \pm 2.56 \mathrm{MPa}$, gold standard $)$, BrackFix $(17 \pm 5.2 \mathrm{MPa})$ and Grengloo ${ }^{\text {Tx }}$ $(19.08 \pm 3.19 \mathrm{MPa})$ was in a clinically adequate range without significant differences. All three products showed significantly higher mean SBS than glass ionomer luting cement ( $8.7 \pm 3.86 \mathrm{MPa}$, zero control) (Fig. 2a). Mean ARI-scores ranged between 4 and 5 in all four products (Fig. 2b), whereas the rate of enamel fractures was higher in Grengloo ${ }^{\text {Tx }}$ (50\%) and Meron (15\%) than in
TB XT and BrackFix ${ }^{\circ}$ (Fig. 2c). Table 1 shows the results for the main effects of comparisons.

\section{Effect of strength enhancing orthodontic bonding systems and rebonding on bonding quality}

When A primer was combined with TB XT, SBS of orthodontic brackets increased compared to TB XT primer and adhesive alone $(20.29 \pm 4.95$ vs. $18.45 \pm 2.56$ $\mathrm{MPa})$, but the difference was not statistically significant (Fig. 3a). In general, rebonding decreased the mean SBS significantly in both AS primer and TB XT adhesive $(16.76 \pm 3.7 \mathrm{MPa})$ and $\mathrm{TB}$ XT primer and adhesive alone $(13.06 \pm 3.19 \mathrm{MPa})$ compared to first bonding. Mean SBS at second bonding was significantly higher in AS primer and TB XT adhesive compared to TB XT alone.

At first bonding, mean ARI-scores of TB XT and AS ranged between 4 and 5 . At second bonding, TB XT showed the same range, while AS and TB XT adhesive showed significantly lower ARI-Scores $(2.63 \pm 1.5)$ suggesting a higher risk for enamel damage (Fig. 3b). In general, the rate of enamel fractures was higher in AS (first bonding: 55\%, rebonding: $21.05 \%$ ) than in TB XT (first bonding: $0 \%$, second bonding: $5 \%$ ), while the difference was significant only at first bonding (Fig. 3c).

\section{Comparison of different rebonding systems}

Processing of bovine teeth with AS $(16.76 \pm 3.70 \mathrm{MPa})$ or AS in combination with $\mathrm{PC}(18.30 \pm 3.99 \mathrm{MPa})$ prior to rebonding led to significantly increased SBS compared 
A

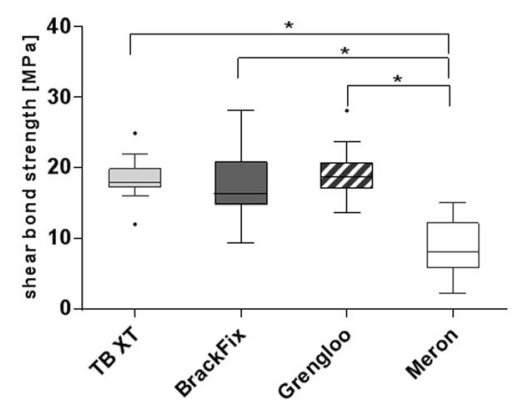

B

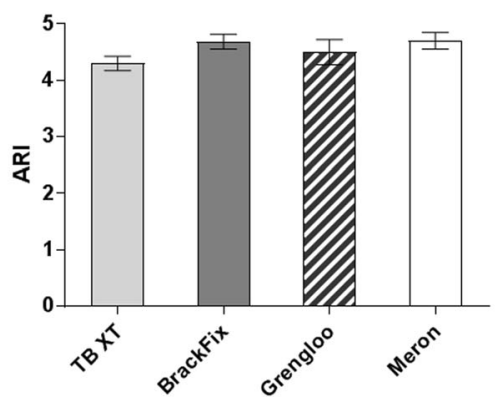

C

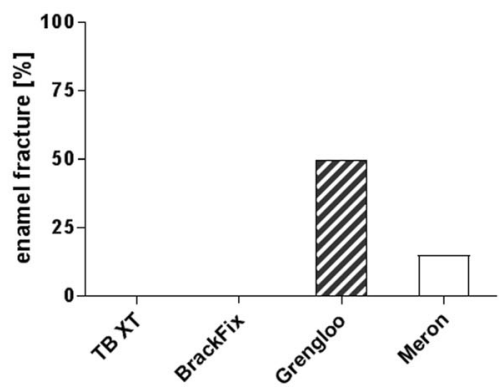

Fig. 2 Comparison of conventional orthodontic bonding systems. a Shear bond strength, $\mathbf{b}$ ARI and $\mathbf{c}$ rate of enamel fractures of orthodontic attachments bonded to bovine incisors with Transbond XT $\mathrm{T}^{\mathrm{M}}(\mathrm{TB} X \mathrm{XT}, n=20)$, BrackFix ${ }^{\otimes}(n=20)$, Grengloo ${ }^{\mathrm{TM}}(n=20)$ and the glass ionomer luting cement Meron $(n=20)$. a Shear bond strength of TB XT, BrackFix ${ }^{\otimes}$ and Grengloo ${ }^{T M}$ were in a clinically adequate range, whereas Meron served as a zero control. b Mean ARI-scores were between 4 and 5. c Enamel fractures were observed in Grengloo ${ }^{\mathrm{TM}}$ (50\%) and Meron (15\%). Data shown as mean \pm SEM or as relative frequency; statistically significant differences $(p \leq 0.05)$ are marked with *

to applying TB XT alone (Fig. 4a). There were no statistically significant differences to the gold standard $(18.45 \pm 2.56 \mathrm{MPa})$.

The use of $\mathrm{PC}, \mathrm{TB}$ XT primer and adhesive did not show significant differences to rebonding with TB XT primer and adhesive alone $(13.57 \pm 2.94$ vs. $13.06 \pm 3.19$ $\mathrm{MPa})$. Leaving out enamel etching led to clinically inadequate SBS in the rebonding procedures with $\mathrm{PC}$ and AS $(8.12 \pm 3.34 \mathrm{MPa})$ as well as PC, TB XT primer and adhesive $(3.7 \pm 1.95 \mathrm{MPa})$. Mean ARI-score ranged between 4 and 5, but was significantly lower in Assure ${ }^{\text {Tw }}$ PLUS $(2.63 \pm 1.54)$ (Fig. 4b). Concerning enamel fractures, there was a higher rate of fractures at rebonding in AS (21.05\%) and in AS in combination with PC (55\%). Enamel fractures in other combinations were absent or the rate was low (TB XT, PC leaving out etching $=5 \%)$ (Fig. 4c).

\section{Discussion}

The present in vitro study aims to evaluate the effect of different bonding and rebonding procedures on shear bond strength (SBS) of orthodontic attachments, adhesive adherence and enamel fractures in rebonding conditions. As orthodontic attachments usually remain in the patient's mouth for about 2 years, adequate bonding strength should not be below 6-10 MPa [37, 38]. Moreover, these values are also required for a permanent retention with fixed orthodontic retainers $[39,40]$.

In our investigation, initial bonding of attachments was performed with TB XT, BrackFix ${ }^{\circ}$ and Grengloo ${ }^{\mathrm{Tx}}$. SBS ranged between 16-18 MPa and can be compared to similar studies [41]. Hence, the clinical relevance is therefore given. The use of AS further increased SBS and also led to a higher enamel fracture rate. So the use of AS at first bonding might remain reserved for complicated bonding situations such as porcelain restorations or saliva contamination.

Rebonding was performed with the adhesive system TB XT in different primer combinations. When rebonding was performed with TB XT alone, SBS decreased for about $5 \mathrm{MPa}$ on overage compared to the gold standard $(13.06 \pm 3.19$ vs. $18.45 \pm 2.56 \mathrm{MPa})$. Previous authors confirm our findings as they found lower SBS in rebonding than in initial bonding $[1,21,24,42]$.

Table 1 Results for the main effects of comparisons 1-3

\begin{tabular}{|c|c|c|c|c|c|}
\hline Comparison & Main effect(s) & $\begin{array}{l}\text { SBS } \\
p \text {-value a }\end{array}$ & $\begin{array}{l}\text { ARI } \\
p \text {-value }\end{array}$ & $\begin{array}{l}\text { Enamel fractures } \\
p \text {-value }\end{array}$ & Pairwise comparisons \\
\hline $\begin{array}{l}\text { Part } 1 \text { - Conventional orthodontic } \\
\text { bonding systems }\end{array}$ & Group (4 levels) & $<0.0001$ & 0.2734 & 0.0054 & $\begin{array}{l}\text { Statistically significant differences } \\
\text { are indicated in Fig. } 2 a-c .\end{array}$ \\
\hline \multirow{3}{*}{$\begin{array}{l}\text { Part } 2 \text { - Strength enhancing } \\
\text { orthodontic bonding systems }\end{array}$} & Primer (2 levels) & 0.0014 & $<0.0001$ & 0.0046 & \multirow{3}{*}{$\begin{array}{l}\text { Statistically significant differences } \\
\text { are indicated in Fig. } 3 a-c .\end{array}$} \\
\hline & Rebonding (2 levels) & $<0.0001$ & 0.0043 & 0.8798 & \\
\hline & Primer*Rebonding & 0.2675 & 0.0003 & 0.1629 & \\
\hline $\begin{array}{l}\text { Part } 3 \text { - Comparison of different } \\
\text { rebonding systems }\end{array}$ & Group (7 Levels) & $<0.0001$ & $<0.0001$ & 0.0008 & $\begin{array}{l}\text { Statistically significant differences } \\
\text { are indicated in Fig. } 4 a-c .\end{array}$ \\
\hline
\end{tabular}

a The $p$-values for the main effects were obtained from a linear regression model

b The $p$-values for the main effects were obtained from a logistic regression model with Firth's bias correction. 
A

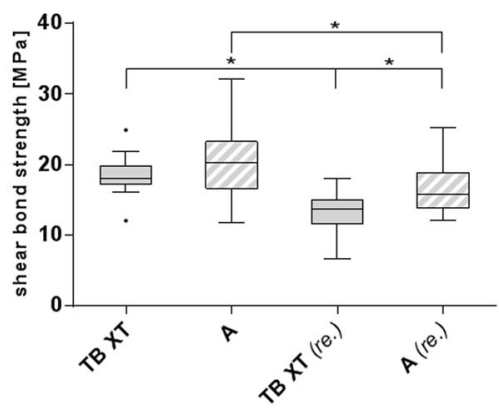

B

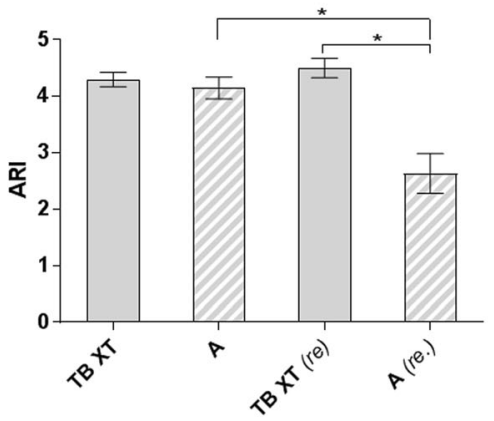

C

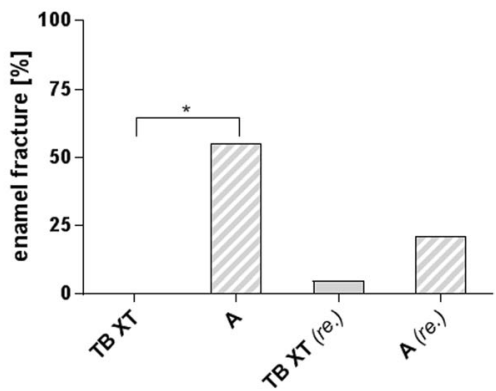

Fig. 3 Comparison of hydrophilic bonding systems. a Shear bond strength, $\mathbf{b}$ ARI and $\mathbf{c}$ rate of enamel fractures of orthodontic attachments bonded to bovine incisors with Transbond XT ${ }^{\mathrm{TM}}$ (TB XT) or Assure ${ }^{\mathrm{TM}}$ PLUS primer and TB XT adhesive at first bonding and at rebonding after artificial bracket loss (each $n=20$ ). a Assure ${ }^{\text {TM }}$ PLUS enhanced shear bond strength at first bonding and at rebonding, whereas rebonding showed in general lower values. b Mean ARI-score was significantly lower at rebonding with Assure ${ }^{\mathrm{TM}}$ PLUS. c The rate of enamel fractures at first bonding was significantly higher in Assure ${ }^{T M}$ PLUS than in TB XT. A = Assure ${ }^{\mathrm{TM}}$ PLUS; re. = rebonding. Data shown as mean \pm SEM or as relative frequency; statistically significant differences $(p \leq 0.05)$ are marked with *

If acid etching was not performed at all, SBS decreased for about $10 \mathrm{MPa}$ when AS and PC primer were applied $(8.12 \mathrm{MPa})$ and for about $15 \mathrm{MPa}$ when $\mathrm{PC}$ and TB XT primer were applied $(3.7 \mathrm{MPa})$. Therefore, the use of the primers PC and TB XT alone cannot be recommended in rebonding because the achieved values were lower than proposed by Reynolds [37].

When AS or AS and PC were used in rebonding, differences in SBS to initial bonding were compensated and the gold standard was reached. However, many studies have shown the benefit of AS in enhancing SBS in initial bonding in ceramic and metallic restorations, but to our knowledge, the impact on rebonding remained unclear [43-46]. Since a higher SBS at rebonding also led to higher rates of enamel fractures in our investigation, bracket rebonding should be done with caution in cases of hydrophilic primers. In vitro studies showed that enamel loss ranged between 7.6-41,6 $\mu \mathrm{m}$ resulting from debonding molar tubes and $18-33 \mu \mathrm{m}$ from debonding ceramic brackets $[47,48]$.

Rüger et al. reported in general a higher risk of enamel tear-outs during debonding at repeated etching, but also showed increased SBS when acid etching was left off $(4.95 \pm 1.22 \mathrm{MPa})$ [49]. The authors postulate, that acid

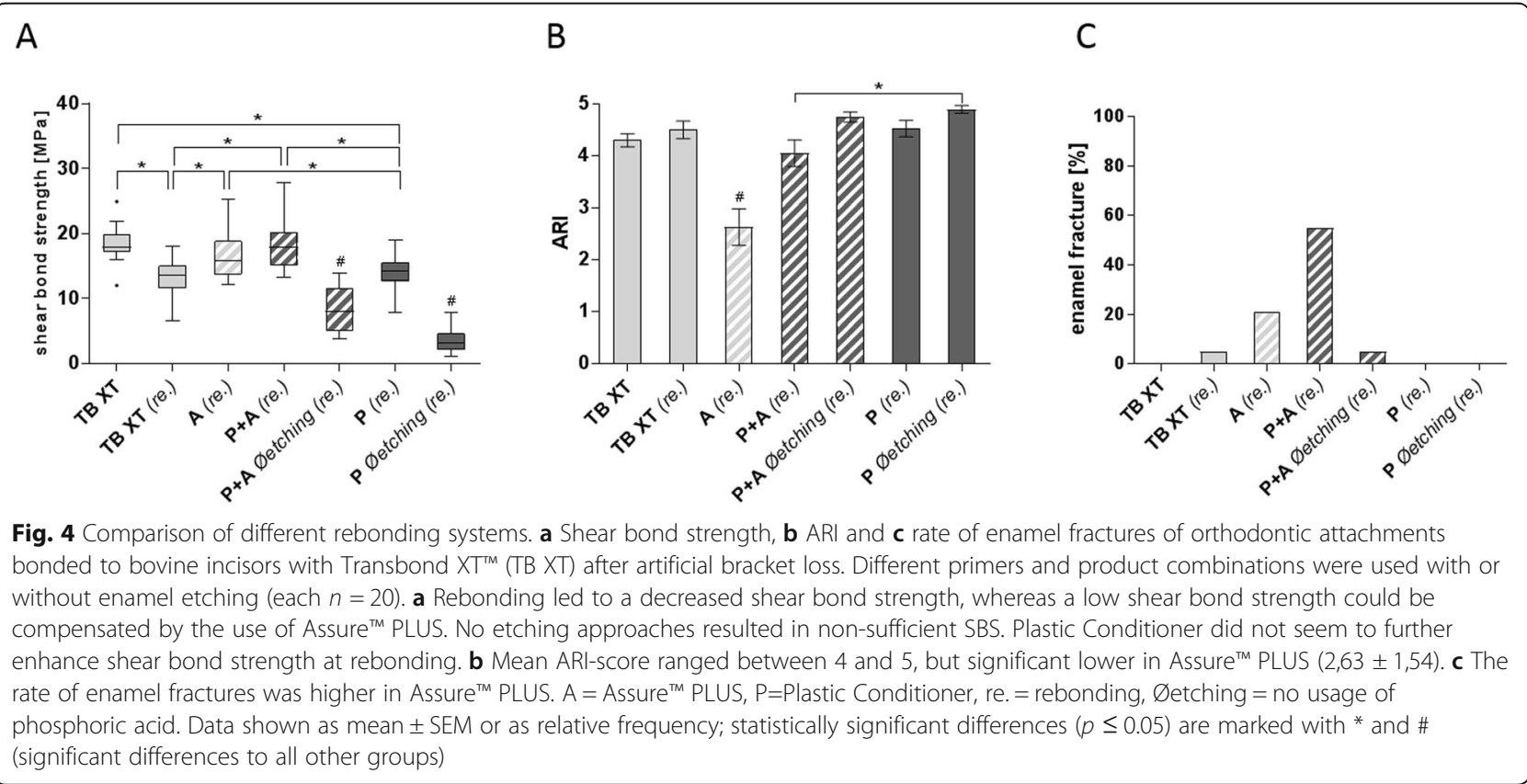


etching could be left off in rebonding, when composite was reduced instead of completely removed [49]. Our results also show, that SBS was reduced, when acid etching was left out and SBS was only clinically adequate, when teeth were processed with AS. However, leaving out acid etching also led to a reduced rate of enamel fractures.

Concerning the application of $\mathrm{PC}$ in rebonding procedures, there is only limited evidence. Egan et al. investigated different rebonding procedures in human teeth and applied a combination of PC and Enhance ${ }^{\mathrm{ma}}$ Adhesion Booster. However, likewise our investigation they didn't find increased SBS [50].

\section{Limitations}

With respect to the findings of this investigation, there are a few limitations to note. First, results should be interpreted with caution as they were of theoretical character and reflect an in vitro approach. It has to be considered, that SBS measured at debonding in vitro is on average $40-57 \%$ higher than measured in vivo [51, 52]. Reasons might be material aging and unpredictable temperature changes in the oral cavity, which can alter material properties and cannot be fully transferred to in vitro approaches [53]. Second, we used bovine incisors in our study and therefore, the results may not be fully transferable to human teeth. Nevertheless, the results of this study can serve as a basis for further prospective research in order to enable reliable assessments and clinical implications about rebonding procedures.

\section{Conclusion}

- Based on the present findings limited rebonding strength can be compensated by the use of hydrophilic priming systems.

- The additional use of plastic conditioners does not seem to enhance bonding strength.

- No etching approaches resulted in non-sufficient bonding strength.

\section{Abbreviations}

SBS: Shear bond strength; ARI: Adhesive remnant index; TB XT: Transbond ${ }^{\text {TM }}$ XT; AS: Assure ${ }^{\mathrm{TM}}$ PLUS; PC: Plastic Conditioner

\section{Acknowledgements}

The authors thank the Otto Schott Institute of Materials Research, University of Jena, Germany and the Medical Faculties of Aachen and Jena, Germany for science support.

\section{Authors' contributions}

$A B, K T$, EW carried out the measurements. IK drafted the first version of the manuscript and worked out literature research. MW worked out the study design. IK, JRB and YW coordinated the study and wrote the final article. MVR and RBC did the statistical analyses. All authors read and approved the final manuscript and made substantial contributions during the review process.

\section{Funding}

The study was funded by the companies $\mathrm{VOCO}^{\circledR} \mathrm{GmbH}$, Cuxhaven, Germany, that was involved in financial and material support, DENTAURUM GmbH \& Co. KG, Ispringen, Germany and 3 M Unitek GmbH, Neuss, Germany, that were involved in material support. None of the mentioned companies was involved in either data collection, analysis and interpretation or the writing of the article. Open access funding provided by Projekt DEAL.

Availability of data and materials

The datasets used and/or analysed during the current study are available from the corresponding author on reasonable request.

Ethics approval and consent to participate

This article does not report on any studies with human participants or animals that were performed by any of the authors.

Consent for publication

Not applicable.

Competing interests

The authors declare that they have no competing interests.

\section{Author details}

${ }^{1}$ Department of Orthodontics, RWTH Aachen University Hospital, Pauwelsstr. 30, 52074 Aachen, Germany. ${ }^{2}$ Department of Medical Statistics, RWTH Aachen University Hospital, Pauwelsstr. 19, 52074 Aachen, Germany.

${ }^{3}$ Department of Orthodontics, Jena University Hospital, An der alten Post 4, 07743 Jena, Germany.

Received: 2 March 2020 Accepted: 1 September 2020

Published online: 05 September 2020

\section{References}

1. Bishara SE, VonWald L, Laffoon JF, Warren JJ. The effect of repeated bonding on the shear bond strength of different orthodontic adhesives. Angle Orthod. 2000;70:435-41.

2. Stasinopoulos D, Papageorgiou SN, Kirsch F, Daratsianos N, Jäger A, Bourauel $C$. Failure patterns of different bracket systems and their influence on treatment duration: a retrospective cohort study. Angle Orthod. 2018;88: 338-47.

3. Linklater RA, Gordon PH. An ex vivo study to investigate bond strengths of different tooth types. J Orthod. 2001;28:59-65.

4. Mohammed R, Abass S, Abubakr N, Mohammed Z. Comparing orthodontic bond failures of light-cured composite resin with chemicalcured composite resin: a 12-month clinical trial. Am J Orthod Dentofac Orthop. 2016;150:290-4.

5. O'Dywer L, Littlewood S, Rahman S, Spencer R, Barber S, Russell J. A multicenter randomized controlled trial to compare a self-ligating bracket with a conventional bracket in a UK population: part 1: treatment efficiency. Angle Orthod. 2016:86:142-8.

6. Adolfsson U, Larsson E, Ogaard B. Bond failure of a no-mix adhesive during orthodontic treatment. Am J Orthod Dentofac Orthop. 2002;122:277-81.

7. Sunna S, Rock W. Clinical performance of orthodontic brackets and adhesive systems: a randomized clinical trial. Br J Orthod. 1998;25:283-7.

8. Roelofs T, Merkens N, Roelofs J, Bronkhorst E, Breuning H. A retrospective survey of the causes of bracket- and tube-bonding failures. Angle Orthod. 2017:87:111-7.

9. Jung M. Survival analysis of brackets and tubes: a twelve-month assessment Angle Orthod. 2014;84:1034-40.

10. Nazir M, Walsh T, Mandall N, Matthew S, Fox D. Banding versus bonding of first permanent molars: a multi-centre randomized controlled trial. J Orthod. 2011;38:81-9.

11. Banks $P$, Elton $V$, Jones $Y$, Rice $P$, Derwent $S$, Odondi $L$. The use of fixed appliances in the UK: a survey of specialist orthodontists. J Orthod. 2010;37:43-55.

12. Mizrahi E. Study, success and failure of banding and bonding. A clinical study. Angle Orthod. 1982;52:113-7.

13. Trimpeneers $L$, Dermaut $L$. A clinical trial comparing the failure rates of two orthodontic bonding systems. Am J Orthod Dentofac Orthop. 1996;110: 547-50

14. Cacciafesta V, Sfondrini M, De Angelis M, Scribante A, Klersy C. Effect of water and saliva contamination on shear bond strength of brackets bonded 
with conventional, hydrophilic, and self-etching primers. Am J Orthod Dentofac Orthop. 2003;123:633-40.

15. Oztoprak M, Isik F, Sayinsu K, Arun T, Aydemir B. Effect of blood and saliva contamination on shear bond strength of brackets bonded with 4 adhesives. Am J Orthod Dentofac Orthop. 2007;131:238-42.

16. Daratsianos N, Schütz B, Reimann S, Weber A, Papageorgiou SN, Jäger A, et al. The influence of enamel sandblasting on the shear bond strengthand fractography of the bracket-adhesive-enamel complex testedin vitro by the DIN 13990:2017-04 standard. Clin Oral Investig. 2019;23:2975-85.

17. Skidmore K, Brook K, Thomson W, Harding W. Factors influencing treatment time in orthodontic patients. Am J Orthod Dentofac Orthop. 2006;129:230-8.

18. Gupta N, Kumar D, Palla A. Evaluation of the effect of three innovative recyling methods on the shear bond strength of stainless steel brackets-an in vitro study. J Clin Exp Dent. 2017;9:e550-5.

19. Basudan A, Al-Emran S. The effects of in-office reconditioning on the morphology of slots and bases of stainless steel brackets and on the shear/ peel bond strength. J Orthod. 2001;28:231-6.

20. Ryf S, Flury S, Palaniappan S, Lussi A, van Meerbeek B, Zimmerli B. Enamel loss and adhesive remnants following bracket removal and various clean-up procedures in vitro. Eur J Orthod. 2012;34:25-32.

21. Nicolás A, Vicente $A$, Bravo $L$. The in vitro effect of repeated bonding on the shear bond strength with different enamel conditioning procedures. Eur J Orthod. 2010;32:291-6.

22. Chung C, Fadem B, Levitt H, Mante F. Effects of two adhesion boosters on the shear bond strength of new and rebonded orthodontic brackets. Am J Orthod Dentofac Orthop. 2000;118:295-9.

23. Regan $D$, LeMasney $B$, van Noort $R$. The tensile bond strength of new and rebonded stainless steel orthodontic brackets. Eur J Orthod. 1993;15:125-35.

24. Kilponen L, Lassila L, Tolvanen M, Varrela J, Vallittu PK. Effect of Removal of Enamel on Rebonding Strength of Resin Composite to Enamel. Biomed Res Int. 2016;2016:1818939. https://doi.org/10.1155/2016/1818939.

25. Noble J, Karaiskos NE, Wiltshire WA. In vivo bonding of orthodontic brackets to fluorosed enamel using an adhesion promotor. Angle Orthod. 2008;78:357-60.

26. Van Landuyt K, Snauwaert J, De Munck J, Peumans M, Yoshida Y, Poitevin A, et al. Systematic review of the chemical composition of contemporary dental adhesives. Biomaterials. 2007;28:3757-85.

27. Vicente A, Bravo L, Romero M, Ortíz A, Canteras M. Effects of 3 adhesion promoters on the shear bond strength of orthodontic brackets: an in-vitro study. Am J Orthod Dentofac Orthop. 2006;129:390-5.

28. Nakabayashi N, Takarada K. Effect of HEMA on bonding to dentin. Dent Mater. 1992:8:125-30.

29. Gonçalves T, KN T, de Oliveira J, Gama L, Bortolini S, Philippi A. Surface treatments to improve the repair of acrylic and bis-acryl provisional materials. Am J Dent. 2018;31:199-204.

30. Perea L, Matinlinna J, Tolvanen M, Lassila L, Vallittu P. Monomer priming of denture teeth and its effects on the bond strength of composite resin. J Prosthet Dent. 2014;112:257-66

31. Wan Abdul Razak W, Sherriff M, Bister D, Seehra J. Bond strength of stainless steel orthodontic brackets bonded to prefabricated acrylic teeth. J Orthod. 2017:44:105-9.

32. Miles P. Indirect bonding--do custom bases need a plastic conditioner? A randomised clinical trial. Aust Orthod J. 2010;26:109-12.

33. Knaup T, Korbmacher-Steiner H, Braun A, Wenzler J, Knaup I, Stein S. Effects of 445-nm diode laser-assisted Debonding of metallic brackets on shear bond strength and enamel surface morphology. Photobiomodul Photomed Laser Surg. 2020;38:160-6.

34. Deutsches Institut für Normung e. V. DIN 13990:2017-04 dentistry - testmethods for shear bond strength of adhesives for orthodontic attachments. 2017.

35. Bishara S, Trulove T. Comparisons of different debonding techniques for ceramic brackets: an in vitro study. Part II. Findings and clinical implications. Am J Orthod Dentofac Orthop. 1990;98:263-73.

36. Edwards D, Berry JJ. The efficiency of simulation-based multiple comparisons. Biometrics. 1987;43:913-28.

37. Reynolds I. A review of direct orthodontic bonding. Br J Orthod. 1974;2:171-8

38. Diedrich P. Die Verbundfestigkeit verschiedener orthodontischer Adhäsive zum konditionierten Schmelz und zur Bracketbasis. Fortschr Kieferorthop. 1981:42:305-20.

39. Reicheneder C, Hofrichter B, Faltermeier A, Proff P, Lippold C, Kirschneck C Shear bond strength of different retainer wires and bonding adhesives in consideration of the pretreatment process. Head Face Med. 2014;28:51. https://doi.org/10.1186/1746-160X-10-51.

40. Wolf M, Schulte U, Küpper K, Bourauel C, Keilig L, Papageorgiou SN, et al. Post-treatment changes in permanent retention. J Orofac Orthop. 2016;77: 446-53. https://doi.org/10.1007/s00056-016-0054-0.

41. Schauseil M, Blöcher S, Hellak A, Roggendorf M, Stein S, Korbmacher-Steiner $\mathrm{H}$. Shear bond strength and debonding characteristics of a new premixed self-etching with a reference total-etch adhesive. Head Face Med. 2016;12: 19. https://doi.org/10.1186/s13005-016-0117-x

42. Eslamian L, Borzabadi-Farahani A, Tavakol P, Tavakol A, Amini N, Lynch E. Effect of multiple debonding sequences on shear bond strength of new stainless steel brackets. J Orthod Sci. 2015;4:37-41.

43. Hadrous R, Bouserhal J, Osman E. Evaluation of shear bond strength of orthodontic molar tubes bonded using hydrophilic primers: an in vitro study. Int Orthod. 2019;17:461-8.

44. Naseh R, Afshari M, Shafiei F, Rahnamoon N. Shear bond strength of metal brackets to ceramic surfaces using a universal bonding resin. J Clin Exp Dent. 2018;10:e739-45.

45. Tayebi A, Fallahzadeh F, Morsaghian M. Shear bond strength of orthodontic metal brackets to aged composite using three primers. J Clin Exp Dent. 2017;9:e749-55.

46. Wongsamut W, Satrawaha S, Wayakanon K. Surface modification for bonding between amalgam and orthodontic brackets. J Orthod Sci. 2017;6: 129-35.

47. Suliman S, Trojan T, Tantbirojn D, Versluis A. Enamel loss following ceramic bracket debonding: a quantitative analysis in vitro. Angle Orthod. 2015;85: 651-6. https://doi.org/10.2319/032414-224.1.

48. Janiszewska-Olszowska J, Tandecka K, Szatkiewicz T, Sporniak-Tutak K, Grocholewicz K. Three-dimensional quantitative analysis of adhesive remnants and enamel loss resulting from debonding orthodontic molar tubes. Head Face Med. 2014;10:37. https://doi.org/10.1186/1746-160X-10-37.

49. Rüger D, Harzer W, Krisjane Z, Tausche E. Shear bond strength after multiple bracket bonding with or without repeated etching. Eur J Orthod. 2011;33: $521-7$.

50. Egan F, Alexander S, Cartwright G. Bond strength of rebonded orthodontic brackets. Am J Orthod Dentofac Orthop. 1996;109:64-70.

51. Hajrassie M, Khier S. In-vivo and in-vitro comparison of bond strengths of orthodontic brackets bonded to enamel and debonded at various times. Am J Orthod Dentofac Orthop. 2007;131:384-90.

52. Pickett K, Sadowsky P, Jacobson A, Lacefield W. Orthodontic in vivo bond strength: comparison with in vitro results. Angle Orthod. 2001;71:141-8.

53. Eliades T, Bourauel C. Intraoral aging of orthodontic materials: the picture we miss and its clinical relevance. Am J Orthod Dentofac Orthop. 2005;127: 403-12.

\section{Publisher's Note}

Springer Nature remains neutral with regard to jurisdictional claims in published maps and institutional affiliations.
Ready to submit your research? Choose BMC and benefit from:

- fast, convenient online submission

- thorough peer review by experienced researchers in your field

- rapid publication on acceptance

- support for research data, including large and complex data types

- gold Open Access which fosters wider collaboration and increased citations

- maximum visibility for your research: over $100 \mathrm{M}$ website views per year

At BMC, research is always in progress.

Learn more biomedcentral.com/submissions 